\title{
Variable withdrawal elevations as a management tool to counter the effects of climate warming in Germany's largest drinking water reservoir
}

\author{
Chenxi $\mathrm{Mi}^{1,2^{*}} \mathbb{0}$, Amir Sadeghian $^{3}$, Karl-Erich Lindenschmidt $^{3}$ and Karsten Rinke ${ }^{1}$
}

\begin{abstract}
Background: Thermal stratification in reservoirs is a significant factor affecting water quality, and can be strongly influenced by climate change and operational strategies. Reservoirs in the temperate zone react most sensitively to climate warming during winter as ice cover and inversed stratification are about to disappear in a warmer world. In this study, two well-established hydrodynamic models, the one-dimensional General Lake Model (GLM) and the twodimensional CE-QUAL-W2 (W2), were used to investigate the response of winter inversed stratification in the Rappbode Reservoir to future climate warming, combined with different water withdrawal elevations.

Results: Under increased air temperature, the duration of inversed stratification is reduced and the inversion phenomenon will entirely disappear under current management if the air temperature is increased high enough (more than $4.5 \mathrm{~K}$ ) in the future. Under strong climate warming, the Rappbode Reservoir will therefore change from a dimictic to a monomictic mixing type. Changing the reservoir management from deep withdrawal (e.g., below $350 \mathrm{~m}$ a.s.l.) to shallow withdrawal elevations (e.g., above $390 \mathrm{~m}$ a.s.l.) reduces internal heat energy stored in the reservoir in summer and prolongs the inversed stratification period in winter. This strategy can retain the dimictic behavior even under strong warming.

Conclusions: Our study indicates that adjusting the withdrawal elevation is an effective management instrument to control the winter conditions and can, in fact, mitigate climate warming effects on winter hydrodynamics by stabilizing the dimictic mixing type.
\end{abstract}

Keywords: Rappbode Reservoir, Inversed stratification, Climate warming, Water withdrawal, Model comparison

\section{Introduction and background}

Thermal stratification is the phenomenon referring to a variation in the water temperature at different depths in a water body, and is the result of changes in water density with temperature [4]. The stratification is a significant factor for the evolution of water quality in lentic waters [5]. For example, because of the stratification, connectivity between the bottom and surface layers

\footnotetext{
*Correspondence: chenxi.mi@ufz.de

${ }^{1}$ Department of Lake Research, Helmholtz Centre for Environmental Research, Magdeburg, Germany

Full list of author information is available at the end of the article
}

is suppressed giving rise to a nutrient-rich but colder hypolimnion and a nutrient-poor but warmer epilimnion [34]. Due to the weakened connectivity, it is difficult to supplement the hypolimnion with oxygen from the atmosphere, which can lead to a serious environmental problem of anoxia in the bottom layer [42]. Additionally, the enhanced stratification throughout summer can lead to an increased occurrence of toxin-producing cyanobacteria in the epilimnion, posing a significant threat to water quality [31]. Furthermore, by influencing the greenhouse gas exchange between the water and atmosphere, stratification can affect the role of aquatic systems in the global carbon cycle [14, 47]. Therefore, concerning 
the importance of stratification for aquatic ecosystems, a large amount of investigations has focused on this phenomenon and its influencing factors. Reservoirs offer opportunities to affect stratification by operational strategies, which are not available for natural lakes, and models can be used to explore the available options.

Based on the stratification patterns [5], most of the freshwater systems in temperate regions are either dimictic or warm monomictic: a dimictic water body can be ice covered in winter and is generally stratified both in summer (direct) and winter (inverse) with turnover mixing in spring and autumn; a warm monomictic water is never ice covered and undergoes only one mixing period in winter in addition to being stratified during the rest of the year. Currently, when evaluating the stratification dynamics in this area, most studies focus on the summer stratification with three identifiable layers, epilimnion, metalimnion and hypolimnion, and distinct water temperature differences along the vertical direction during this period [18, 22, 23, 30, 37]. However, little attention has been specifically given to the winter inversed stratification in dimictic waters and its influencing factors.

For dimictic water bodies, the surface water temperature in winter is lower than the bottom layer which causes the winter inversed stratification [27]. This inversed stratification is a prerequisite for the formation of an ice cover $[5,29]$. The winter inversed stratification (and prolonged ice cover) can cause low oxygen and fish kills during long winters, which then can lead to increased grazing of zooplankton on phytoplankton in the following period (and thus increased water quality). Moreover, the existence of the inversion is important evidence in distinguishing between dimictic and monomictic waters. Due to global warming trends over the last decades, the winter inversed stratification and ice cover have been shown to be reduced or have even disappeared in numerous lakes around the world, leading to potential changes of mixing patterns from dimictic to monomictic types $[1,17$, 41]. By employing a 1D hydrodynamic model, Peeters et al. [33] simulated the thermal structure of Lake Zurich over half a century and predicted that under substantially increasing air temperatures in the future, the winter inversion will disappear resulting in the lake shifting from being generally dimictic to generally monomictic. The disappearance of the winter inversion and the subsequent changes in thermal patterns due to climate warming have a negative influence on the hypolimnetic oxygen concentration and can even change the available habitat for aquatic organisms $[17,33]$. Under high greenhouse gas emissions in the absence of climate mitigation polices, the global average air temperature may increase by $5{ }^{\circ} \mathrm{C}$ by the end of the twenty-first century [15]. Concerning the importance of the winter inversed stratification for aquatic systems, there is a need to comprehensively illustrate how the inversion responds to such a noticeable warming trend and whether anthropogenic management practices can influence the inversion so as to mitigate the negative effect caused by global warming.

Among various management strategies for waters, selective water withdrawal is considered to be an effective method to control the thermal stratification for meeting the requirements of different usages. For example, Casamitjana et al. [10] applied a one-dimensional model (DLM) to elucidate the response of the thermal structure of Boadella Reservoir to different withdrawal scenarios. The results show that the withdrawal location determines the thermocline depth and the hypolimnion volume; Çalıskan and Elçi [9] investigated the influence of selective withdrawal on the hydrodynamics of Tahtali Reservoir and concluded that hypolimnetic withdrawal is the most effective choice to encourage water mixing and reduce anoxia; Weber et al. [45] developed an optimization withdrawal strategy which can automatically determine the withdrawal elevation to modify the thermal structures for different water usages. However, all such previous studies focused on the effect of selective withdrawal on summer stratification and did not take the winter inversed stratification into account.

In this study, two well-established hydrodynamic models (i.e., General Lake Model and CE-QUAL-W2) were selected to elucidate the response of winter inversed stratification in the Rappbode Reservoir to future climate warming combined with different water withdrawal elevations. Considering the importance of ice phenology for the temperature inversion, the ice cover (duration and thickness) is also included in the scenarios. Rappbode Reservoir is the largest drinking water reservoir in Germany and supplies drinking water to more than 1 million people. A previous study predicted that by the end of this century, the winter stratification will completely disappear in most of the deep waters in this region as a result of global warming, which will severely threaten their aquatic ecosystems [24]. It is expected that our study will help reservoir operators effectively control the winter inversed stratification so as to mitigate the negative influence caused by the increase in air temperature. Additionally, the two models (General Lake Model and CE-QUAL-W2) are widely used in research to analyze the vertical stratification and thermal dynamics and both are distributed as open-source software. This study provides an excellent opportunity to compare and evaluate the models' performances in detail, which will benefit researchers for model selection and application. Furthermore, simulation results are more reliable if they are supported by several models, so that the outcome becomes independent of one specific model. Additionally, from 
the comparison of results, the strengths and weaknesses of each model can be clearly seen and it will help developers improve and enhance the models in the future.

\section{Methods}

\section{Study site}

The Rappbode Reservoir is located in the eastern Harz Mountains and has a maximum volume of $1.13 \times 10^{8} \mathrm{~m}^{3}$. The crest elevation of the reservoir is $423.6 \mathrm{~m}$ a.s.l. and its maximum depth is $89 \mathrm{~m}$. It is the largest drinking water reservoir in Germany, supplying drinking water to more than 1 million people in central eastern Germany (Fig. 1, [36]). The reservoir is the core of the Rappbode system, a network of six water bodies used for flood protection, environmental flows, hydropower, recreation and drinking water supply. It receives water from three smaller upstream reservoirs (Königshütte Reservoir, and the Hassel and Rappbode auxiliary reservoirs). The reservoir has five outlets at different elevations (360-400 m a.s.l in $10 \mathrm{~m}$ intervals) for raw water discharge. The outlets with the elevation of 360,370 and $380 \mathrm{~m}$ a.s.l are used for most of the time. The top two outlets (390 and $400 \mathrm{~m}$ a.s.l) are only open in late December and early January each year. There is also an additional outlet into the downstream Wendefurth Reservoir from an elevation of $345 \mathrm{~m}$ a.s.l. which is active all the time. The Rappbode Reservoir is a typical dimictic water body with mixing in spring and autumn. It experiences strong stratification in summer and weaker stratification in winter with an ice cover in some years. The mean water residence time of the reservoir is a little more than 1 year (380 days).

\section{Numerical models}

We intentionally used two lake models in our study to quantify the variability of their outcomes due to different model structures. We selected two established, open source and broadly accepted models for our study, the General Lake Model (hereafter GLM) and CE-QUALW2 (hereafter W2). The main difference between the two models can be seen in Table 1 .

1. GLM is a one-dimensional (1D) hydrodynamic model developed by the Aquatic EcoDynamics Research group at the University of Western Australia (http://aed.see.uwa.edu.au/research/models/ $\mathrm{GLM} / ;$ [21]). It simulates the vertical stratification and mixing of lakes, taking the influence of inflows/ outflows, surface heating and cooling and ice cover fraction into account. The code of GLM is open source which can be freely downloaded from GitHub (https://github.com/AquaticEcoDynamics/GLM).

GLM uses a flexible Lagrangian layer structure, i.e., thickness and volume of each layer can be contracted

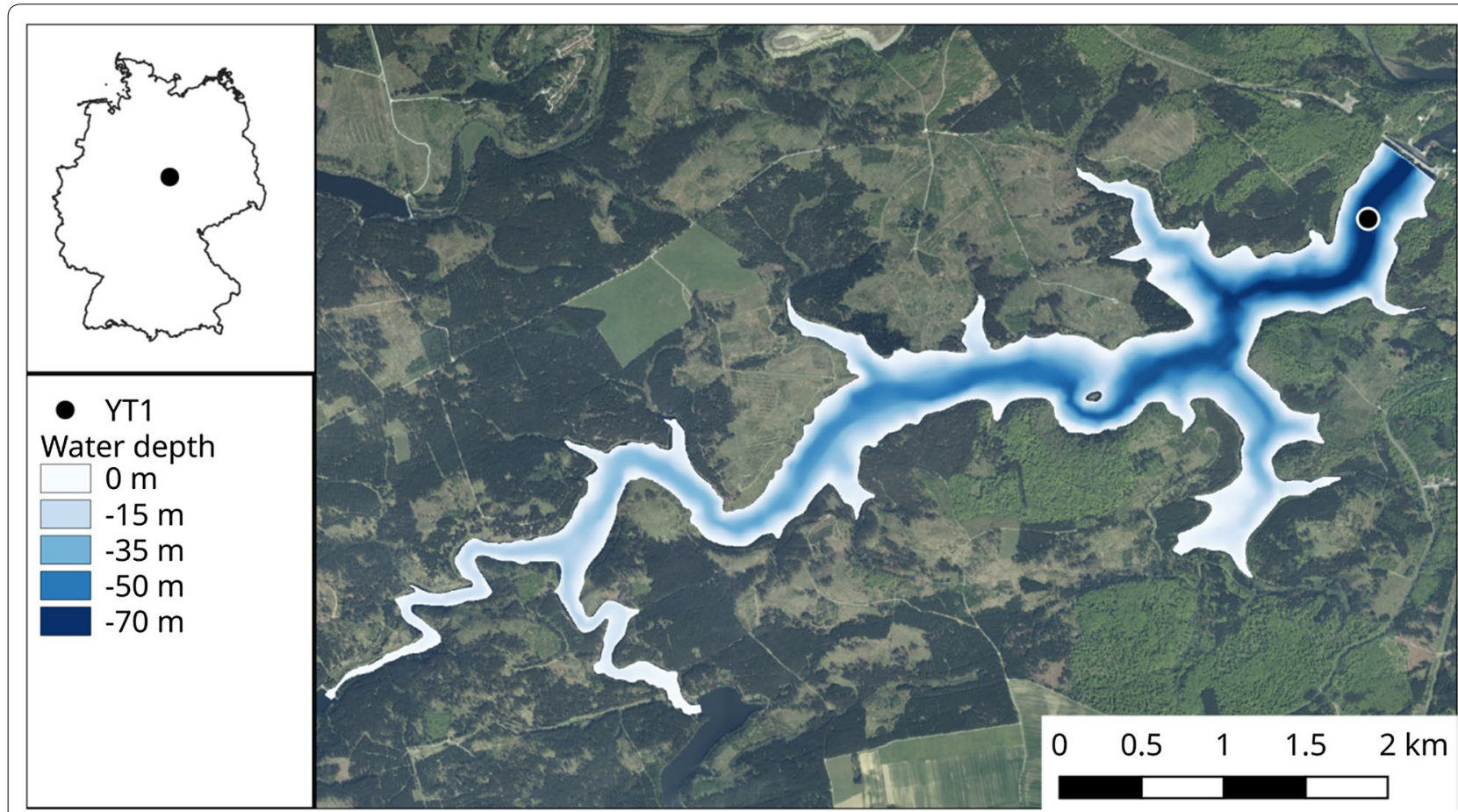

Fig. 1 Map of Germany (top left). The black point indicates the location of the Rappbode Reservoir within Germany. In the bathymetric map of the Rappbode Reservoir (right), the black point shows the monitoring location for water temperature 
Table 1 Comparison of main features of the used models GLM and W2

\begin{tabular}{lll}
\hline Feature & GLM & W2 \\
\hline Dimensionality & DD & 2D \\
Layer grid & Lagrangian & Eulerian \\
Respository & http://aed.see.uwa.edu.au/research/models/GLM/ & http://www.cee.pdx.edu/w2/ \\
Geometric input & hypsographic curve & Topographic map and/or sediment range surveys \\
Meteorological input & Shortwave radiation, cloud cover, air temperature, relative & Shortwave radiation, cloud cover, air temperature, dew \\
& humidity, wind speed, precipitation & point temperature, wind speed, wind direction, precipi- \\
& & tation \\
Reference & {$[30,35]$} & Sadeghian et al. [38]; [6]
\end{tabular}

Table 2 Summary of the model boundary conditions

\begin{tabular}{lll}
\hline Boundary condition & Frequency & Data source \\
\hline Wind speed & Hourly & Station 1, Station 2, Station 3 \\
Wind direction & Hourly & Station 1, Station 2, Station 3 \\
Air temperature & Hourly & Station 1, Station 2, Station 3 \\
Relative humidity & Hourly & Station 1, Station 2, Station 3 \\
Shortwave radiation & Hourly & Station 1, Station 2, Station 3 \\
Precipitation & Hourly & Station 2, Station 3 \\
Cloud & Hourly & Station 3 \\
Inflow discharge & Daily & Reservoir authority (Talsperrenbetrieb Sachsen-Anhalt) \\
Inflow temperature & Daily & Station 2 \\
Outflow discharge & Daily & Reservoir authority (Talsperrenbetrieb Sachsen-Anhalt)
\end{tabular}

Station 1: Monitoring station in the central basin of the Rappbode Reservoir; Station 2: Monitoring station at the Rappbode auxiliary reservoir; Station 3: German Weather Service station at Harzgerode

and expanded dynamically during the runtime of the model. The minimum and maximum layer thickness can be adjusted by the user. Each layer has homogenous physical properties [35].

GLM has been widely used to compute the vertical profiles of water temperature and stratification phenology in different water bodies [34, 42, 45]. In a large multiple lake intercomparison study, GLM was shown to reproduce stratification dynamics in various lakes without local calibration [7]. The model is also successfully applied to simulate ice dynamics [8, 48]. Three components of ice are included in GLM: black ice (formed at the ice-water interface), white ice (generated because of snowfall) and snow cover. Further details on the ice dynamics and modeling of the hydrodyanmics can be found in the GLM manual [21] and in Hipsey et al. [20].

2. W2 is a two-dimensional, laterally averaged, hydrodynamic and water quality model. The hydrodynamics component of the model can predict surface water level elevations, flow velocities and water temperatures varying in the longitudinal and vertical directions. The model conceptualizes water bodies as a grid discretized as vertical columns and horizontal rows. The cell widths can vary spatially to match the cross-sectional width of the water body at the cell location.

W2 is a widespread model and has been successfully applied to various lakes, reservoirs and river systems $[6,12,39]$. Through several decades of model development, W2 has an up-to-date user manual [13] and an active user forum. The source code is freely available with clear comments allowing the extension and application of new formulations and algorithms.

\section{Model setup and input data}

The input files for running the two models include time series of meteorological data, hydrological data for inflows and outflows as well as the reservoir bathymetry describing the elevation-area-volume relationship. An overview of such files can be seen in Table 2. The hydrological and bathymetry data were provided by the reservoir authority of the state of Saxony-Anhalt (Talsperrenbetrieb Sachsen-Anhalt). The water temperature of inflows was obtained from a YSI-6200 probe deployed in the tributaries of the reservoir (see [36]). 
As a 1D model, the model structure of GLM is based on the hypsographic information and user-defined layer properties in terms of maximum number of layers as well as maximum and minimum layer thicknesses. Based on experience and initial testing, the three layer parameters shown above were set to $500,0.5 \mathrm{~m}$ and $0.1 \mathrm{~m}$, respectively.

The Rappbode Reservoir was discretized in W2 using 34 segments along the longitudinal directions of the main stem and side branches (see Fig. 2). Some of the segments, segments $1,24,25,29,30$ and 34 , serve as boundary condition segments, at the model edges and between branches, hence they do not appear in the plan view of the segment discretization. For the discretization in the vertical dissection, the thickness of the top eight rows is $0.25 \mathrm{~m}, 0.5 \mathrm{~m}$ for the next six rows and $1 \mathrm{~m}$ for the remaining rows down to the reservoir bottom.

The meteorological input data, air temperature, wind speed, wind direction, shortwave radiation and relative humidity, were obtained from a monitoring buoy deployed in the central basin of the Rappbode Reservoir (see [36]). High-frequency observed data (every $10 \mathrm{~min}$ )

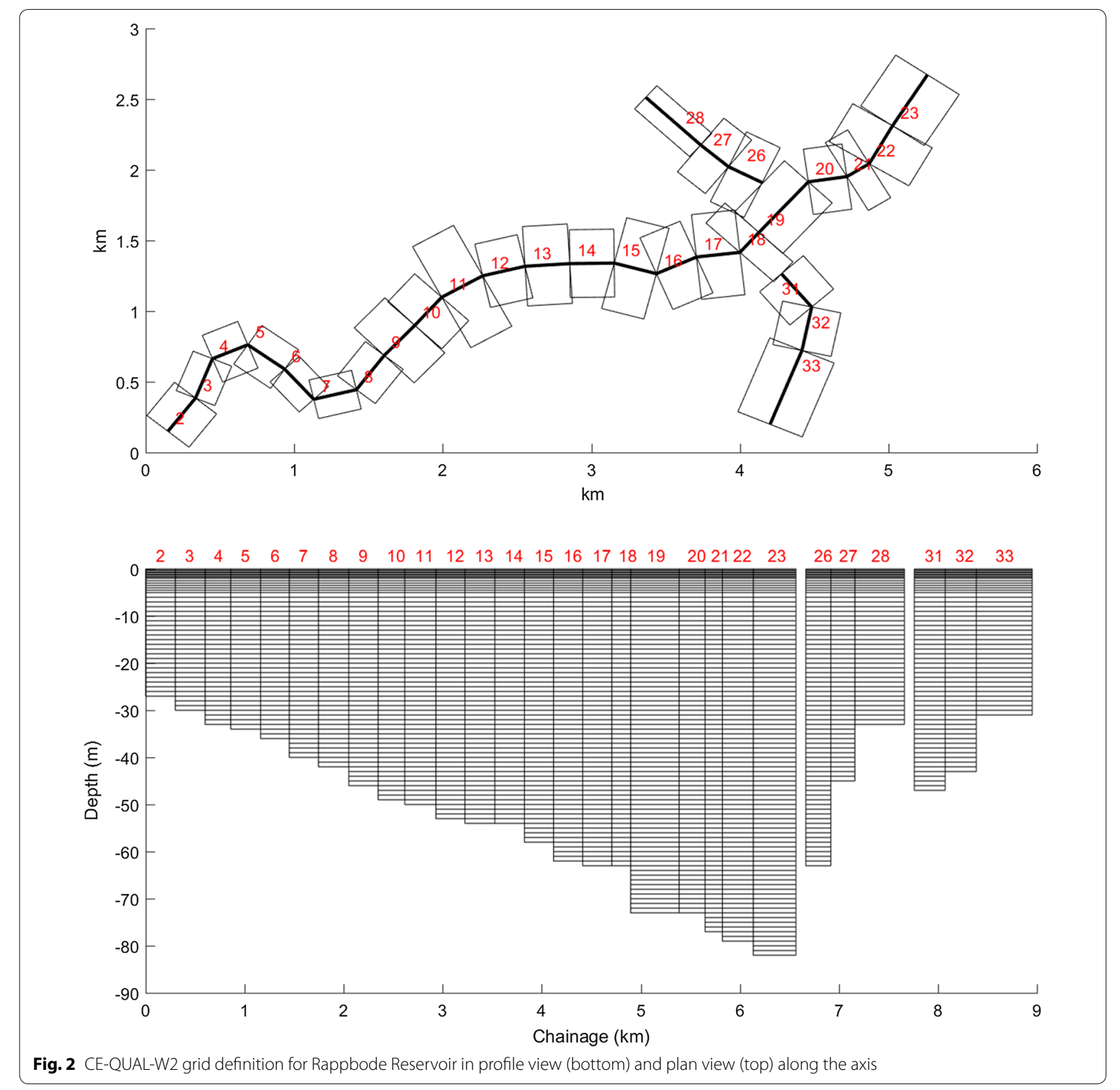


were averaged to hourly values for the simulations. A small amount of missing values was filled with measurements from a nearby observatory at the Rappbode auxiliary reservoir $[19,36]$ or from the German Weather Service station at Harzgerode $(15 \mathrm{~km}$ away from the research area). The precipitation values were primarily drawn from the Harzgerode station because of sensor failures at the measurement buoy and the gaps were filled from data recorded at the Rappbode auxiliary reservoir. The cloud cover fraction data were obtained from the Harzgerode station. All meteorological stations delivered air humidity as relative humidity, but $\mathrm{W} 2$ requires dew point temperature as input. We calculated dew point temperature from relative humidity based on the formula from Lawrence [26]:

$$
\mathrm{Dp}(T, \mathrm{RH})=\frac{\lambda\left(\ln \left(\frac{\mathrm{RH}}{100}\right)+\frac{\beta T}{\lambda+T}\right)}{\beta-\left(\ln \left(\frac{\mathrm{RH}}{100}\right)+\frac{\beta T}{\lambda+T}\right)},
$$

where $\mathrm{Dp}(T, \mathrm{RH})$ is the dew point temperature (in $\left.{ }^{\circ} \mathrm{C}\right)$, $\mathrm{RH}$ is the relative humidity (in \%), $\mathrm{T}$ is the air temperature (in ${ }^{\circ} \mathrm{C}$ ) and the values for the coefficients $\lambda$ and $\beta$ are $243.04{ }^{\circ} \mathrm{C}$ and 17.625 , respectively.

The time step of the simulation output was $1 \mathrm{~h}$, which allows us to capture the sub-daily changes of water temperature and ice cover. Water temperature profiles extending from the water surface to the bottom layer were available for Rappbode Reservoir. The profiles were recorded using high-resolution CTD measurements with a Hydrolab DS5 probe and used for model calibration. Such data were also used for the model initializations, i.e., the vertical profile of water temperature at the beginning of the simulation. Because the Rappbode Reservoir is a typical freshwater system with low conductivity, the salinity in the models was set to 0 .

\section{Model calibration}

The models were run from January 2, 2015 until April 30,2017 . This period was selected because it included a rather mild winter $(2015 / 2016)$ and a cold winter $(2016 / 2017)$ and because high-quality observation data were available from this time. For GLM, aside from a few site-specific settings, calibration of physical parameters is usually not required, as the process parameters have a solid empirical or physical basis and are independent of the local characteristics of the lake and its climate [7, 35]. In accordance with the study of Weber et al. [45], we therefore kept the parameter values the same, as recommended in the scientific manual (see [21]) except for the wind factor (correcting for wind speed) and the averaged background light attenuation, which are considered to be site specific.
For the W2 model calibration, the effects of wind and solar radiation are the most important factors influencing the mixing and heat budget of Rappbode Reservoir. The influence of these two factors is adjusted using the parameters WSC (wind sheltering coefficient) and SHADE (shading coefficient). The light extinction coefficient EXT is also an important parameter, since it controls the amount of solar radiation penetrating the water column from the water surface. Given the minimal calibration of a few site-specific parameters in each model and the fact that both models were shown to have a transferable (i.e., site-independent) parameterization, we did not perform a separate model validation on further observational data.

The root-mean-square error (RMSE) of water temperature was used for model calibration. It has been widely accepted as a good indicator for assessing the geoscientific modeling performance [11].

\section{Scenarios}

To systematically analyze the effects of withdrawal elevation on stratification and mixing regime and to elucidate the management options to influence the winter conditions in the reservoir, we defined two scenarios:

S1: influencing ice dynamics by withdrawal regime. The established model was run with withdrawal elevation varying from the bottom (339 m a.s.l) to the surface $(409 \mathrm{~m}$ a.s.l) in intervals of $1 \mathrm{~m}$, i.e., in total 71 simulations. In this scenario, time-dependent withdrawal discharge was kept the same as in the reference simulation, but all withdrawn water was taken from one single depth as specified in the respective scenario case. Note that in the scenario, all water is withdrawn from one outlet depth and never two separate outtake flows, e.g., one for drinking water and another one for downstream discharge. Since ice formation was only observed in winter $2016 / 2017$, the first scenario was analyzed by exclusively evaluating conditions in this winter by calculating the number of days with ice cover, dates of ice-on and ice-off, as well as mean and maximum ice thicknesses.

S2: mixing regimes under different withdrawal and warming regimes. In the second scenario, we focused on the combined influence of air temperature increase and withdrawal elevation on the duration of inversed stratification. We identified the mixing regime of the reservoir by the occurrence of inversed stratification, i.e., if the inversed stratification occurred in winter, the reservoir was regarded as a dimictic water; if not, it was regarded as a monomictic water body. In this scenario, we created a series of simulations for the whole study period (Jan 2015-April 2017) and increased air temperature from $+0.25(\mathrm{~K})$ to $+5(\mathrm{~K})$ in intervals of $+0.25(\mathrm{~K})$ and withdrawal elevation from 339 to $409 \mathrm{~m}$ in intervals of $1 \mathrm{~m}$. 
In the climate scenarios, we kept the relative humidity in GLM the same as in the original measurements and adjusted dew point temperature in W2 based on Eq. (1) so that relative humidity was the same in both model runs. Just like in the first scenario, all withdrawn water is taken from one elevation at one site. All combinations resulted in a series of 1420 simulations, which were evaluated by both models. We then calculated the number of days with inversed stratification (i.e., the duration of inversed stratification) for each simulation.

Note that temperature differences are given in Kelvin while simulated temperatures are given in degrees Celsius. The R package "glmtools", combined with other customized R code, was applied for executing GLM and analyzing the simulations [35, 46]. More details about the package can be found at GitHub (https://github.com/ USGS-R/glmtools). MATLAB was used to analyze the W2 output.

\section{Results}

\section{Model calibration}

The parameters used in the two models are shown in Table 3 . Both models were able to accurately reproduce the water temperature and stratification phenology of the Rappbode Reservoir, with good agreement between simulated and observed water temperature profiles. For the whole time series, the mean water temperature simulated by GLM and W2 were $6.18{ }^{\circ} \mathrm{C}$ and $5.82{ }^{\circ} \mathrm{C}$, respectively, which are very close to the observed value of $6.17{ }^{\circ} \mathrm{C}$. The overall RMSE for both models is less than $1 \mathrm{~K}$, which indicates a high accuracy of the simulations (Fig. 3). Both models successfully reproduced seasonal variations of water temperature for the top layer (at depth $1 \mathrm{~m}$, see Fig. 4). The models slightly overestimated the metalimnetic water temperature in the summer and early autumn (depth of $23 \mathrm{~m}$, Fig. 4), whereby GLM showed a more pronounced overestimation in

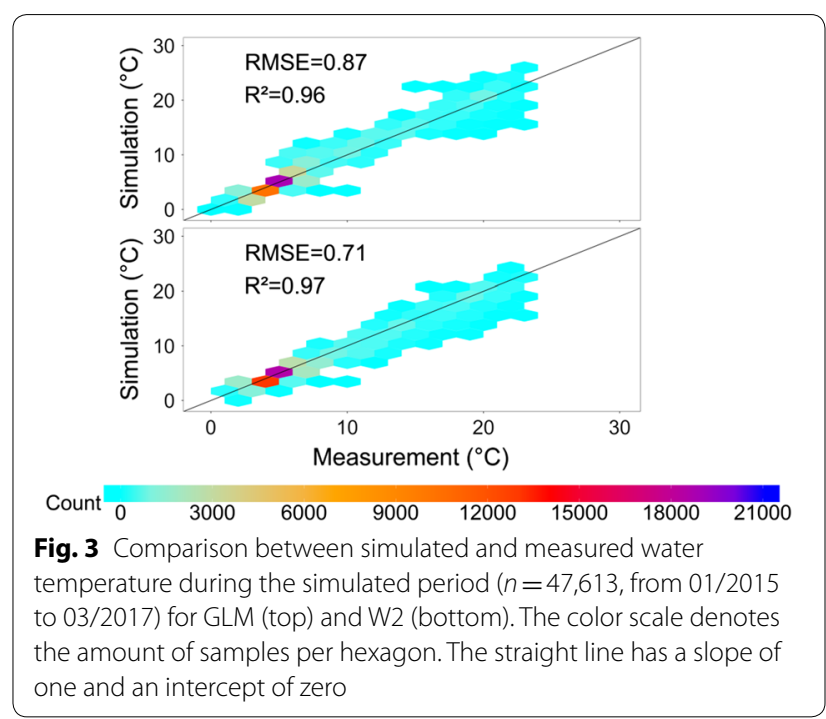

Table 3 List of parameters used in the two models

\begin{tabular}{|c|c|c|c|}
\hline Model & Parameter & Description & Value \\
\hline GLM & $C_{K}$ & Convective overturn coefficient (-) & 0.2 \\
\hline GLM & $C_{\mathrm{KH}}$ & Kelvin-Helmholtz turbulent billows (-) & 0.3 \\
\hline GLM & $C_{W}$ & Wind stirring coefficient (-) & 0.23 \\
\hline GLM & $K_{w}$ & Averaged background light attenuation $\left(\mathrm{m}^{-1}\right)$ & 0.83 \\
\hline GLM & $C_{E}$ & Latent heat transfer coefficient (-) & 0.0013 \\
\hline GLM & $C_{H}$ & Sensible heat transfer coefficient $(-)$ & 0.0013 \\
\hline GLM & $C_{D}$ & Coefficient for transfer of momentum (-) & 0.0013 \\
\hline GLM & $F_{\text {wind }}$ & Wind factor $(-)$ & 0.89 \\
\hline GLM & $F_{\mathrm{sw}}$ & Shortwave radiation factor $(-)$ & 1 \\
\hline W2 & WSC & Wind sheltering coefficient (-) & 1 \\
\hline W2 & SHADE & Shade fraction coefficient (-) & 1 \\
\hline W2 & CBHE & Coefficient of bottom heat exchange $\left(\mathrm{W} \mathrm{m}^{-2}{ }^{\circ} \mathrm{C}^{-1}\right)$ & 0.3 \\
\hline W2 & TSED & Sediment temperature $\left({ }^{\circ} \mathrm{C}\right)$ & 8 \\
\hline W2 & TSEDF & Heat lost to sediments that is added back to water column & 1 \\
\hline W2 & $\mathrm{EXH} 2 \mathrm{O}$ & Light extinction for pure water $\left(\mathrm{m}^{-1}\right)$ & 0.4 \\
\hline W2 & BETA & Fraction of incident solar radiation absorbed at the water surface & 0.45 \\
\hline W2 & BETAI & Fraction of solar radiation absorbed in the ice surface & 0.6 \\
\hline W2 & ALBEDO & Albedo of ice & 0.25 \\
\hline
\end{tabular}

W2 was applied with standard settings for freshwater systems. Note that because of the characteristics of both lake models, settings for specific parameters can have slightly different values due to differences in the underlying model equations 


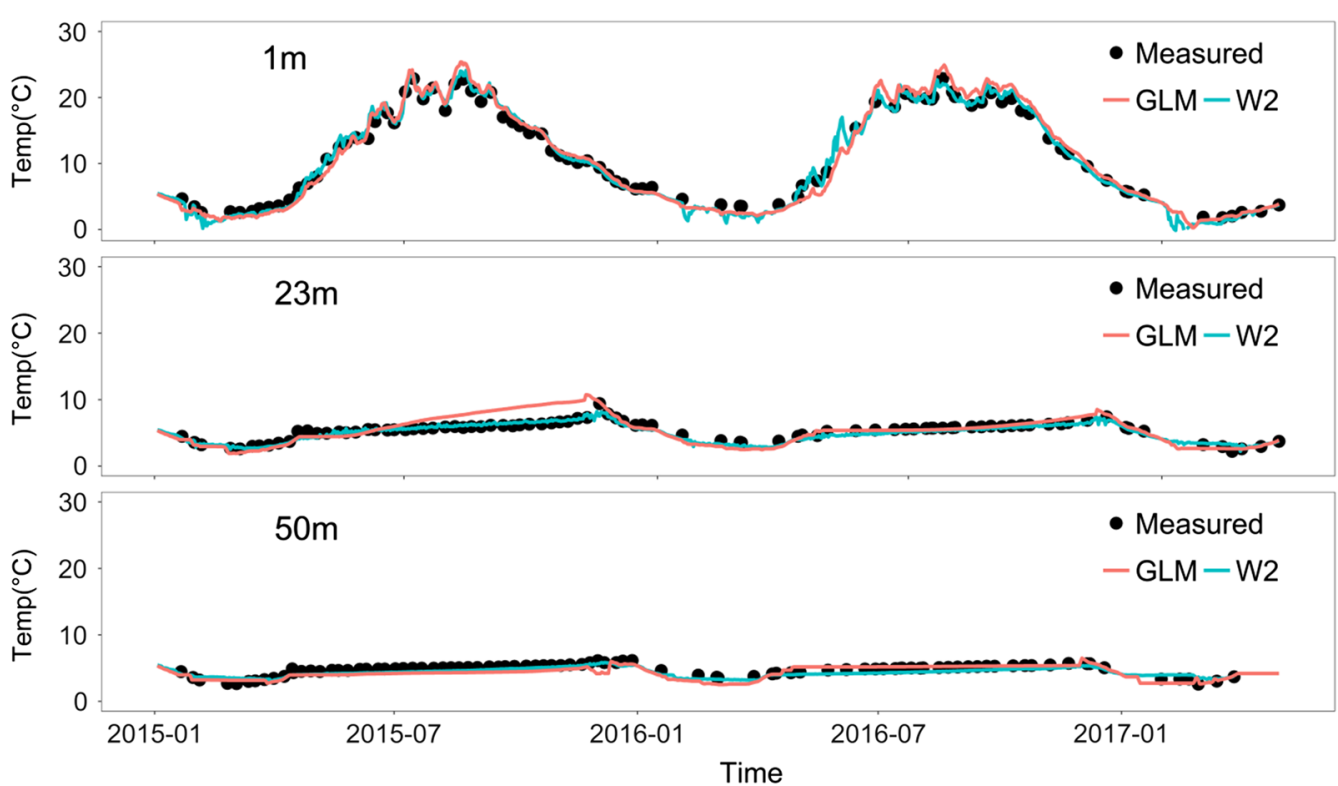

Fig. 4 Simulated and measured water temperatures at 1 m, 23 m, and 50 m depth

2015. Both of them performed well in calculating the hypolimnetic temperature (depth of $50 \mathrm{~m}$, Fig. 4). At the depth of $1 \mathrm{~m}$, the maximum observed water temperature was reached between July and August. For the depth of $23 \mathrm{~m}$, it was delayed toward November. This lag of the maximum temperature was also accurately captured by the two models.
The comparison of simulated and observed ice cover for both models is shown in Fig. 5. For W2, there were 52 days of ice duration in the 2015/2016 winter, although no ice formation was observed in this winter. But both models successfully captured the observed ice cover for the 2016/2017 winter (Fig. 5). For GLM, the ice-on date was well reproduced on 23 January but the ice-off was

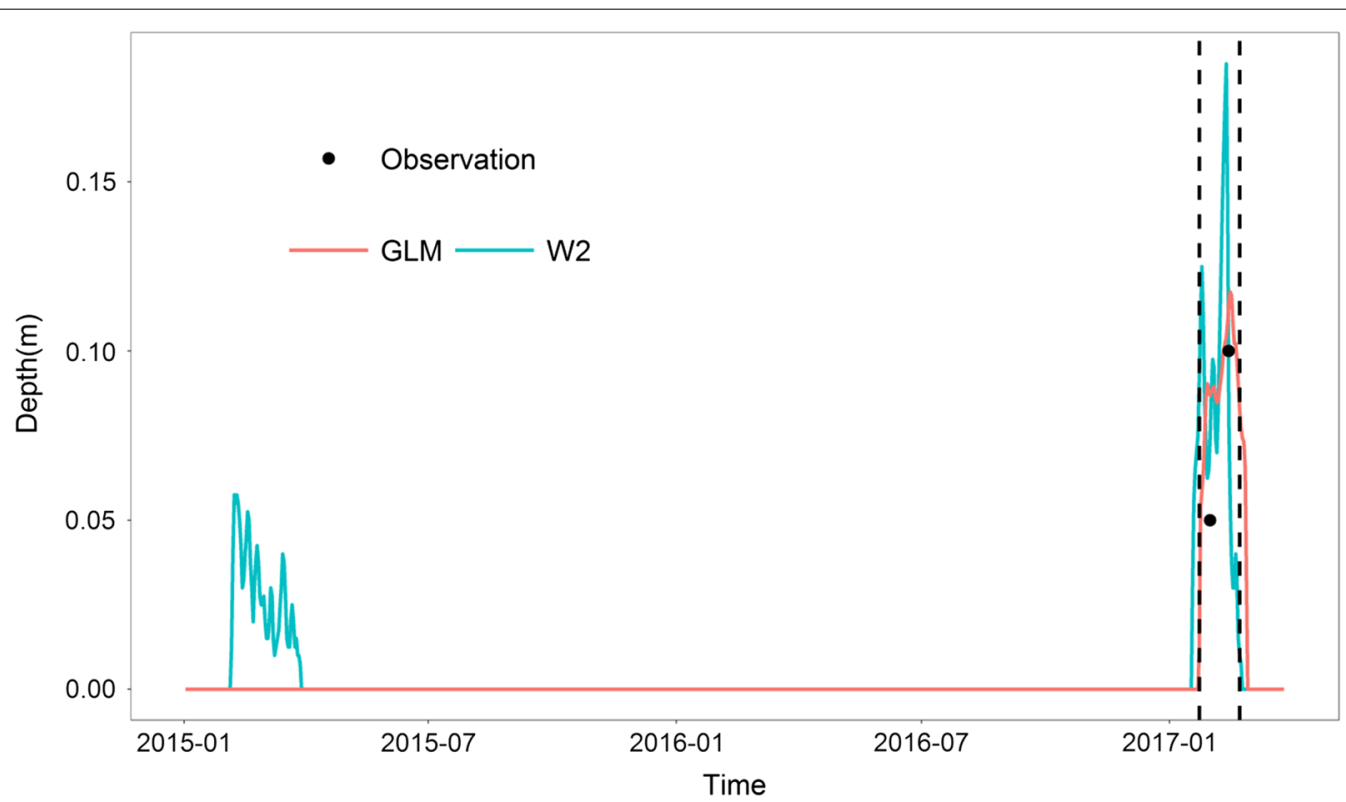

Fig. 5 Simulated ice cover from W2 and GLM during the winters 2015/2016 and 2016/2017. The observed ice-on and ice-off dates are indicated by the vertical dashed lines. The two black dots indicate the measured ice depth on 2017-01-31 (5 cm) and 2017-02-14 $(10 \mathrm{~cm})$ 
simulated 5 days later than the observation. By contrast, W2 exactly captured the observed ice-off date, but simulated 5 days earlier for the ice-on date. Ice thickness was observed two times on January 31 and February 14, 2017 and was measured to be $5.0 \mathrm{~cm}$ and $10.0 \mathrm{~cm}$, respectively (Fig. 5). GLM simulated ice thickness on these dates as $8.7 \mathrm{~cm}$ and $11.5 \mathrm{~cm}$, and W2 thicknesses of $7.5 \mathrm{~cm}$ and $8 \mathrm{~cm}$, respectively. The results in Fig. 5 also show that the simulated maximum ice thickness in 2017 appeared roughly at the same time in the two models (February 15 for GLM and February 12 for W2). However, the maximum thickness by W2 was significantly larger than that by GLM $(18.5 \mathrm{~cm}$ for the former and $11.7 \mathrm{~cm}$ for the latter).

\section{Scenario S1: influencing ice dynamics by withdrawal regime}

GLM and W2 performed differently when simulating ice cover under changing withdrawal elevations. From GLM, a tendency of earlier ice-on, delayed ice-off, and consequently longer ice duration was predicted with a higher withdrawal elevation (Fig. 6). The duration of ice cover increased from less than 37 days (withdrawal elevation below $380 \mathrm{~m}$ a.s.l.) to 39 days (withdrawal elevation at $401 \mathrm{~m}$ a.s.l) and further to 41 days (withdrawal elevation $408 \mathrm{~m}$ a.s.l). It is reasonable to expect that a longer ice season is linked to larger ice thicknesses and vice versa. This is verified by our results showing that the mean and maximum ice thicknesses are consistent with ice duration: the Pearson correlation coefficient between mean ice thickness and ice duration was $0.91(p<0.05)$; the coefficient between the maximum thickness and the duration is $0.96(p<0.05)$. By contrast, W2 was less sensitive to different withdrawal elevations. The ice duration was 33.5 days under bottom withdrawal (339 $\mathrm{m}$ a.s.l.) and increased very slightly to 34.25 days under top withdrawal (409 $\mathrm{m}$ a.s.l.). Similarly, the mean and maximum ice thicknesses calculated by W2 also remained rather stable under different withdrawal elevations. In line with the calibration results, the maximum thickness predicted by W2 was noticeably higher than that from GLM over the range of withdrawal elevations applied (Fig. 6).

\section{Scenario S2: mixing regimes under different withdrawal and warming regimes}

The duration of the inversed winter stratification in both years decreased with deeper withdrawal elevation and increasing air temperatures (Figs. 7, 8). As a matter of course, the inversion phenomenon can entirely disappear if the air temperature is increased high enough. At a warming by $3.5 \mathrm{~K}$, for example, results from both the models showed that the winter inversion disappeared completely for the mild winter of 2015/2016 and the reservoir resorts to a monomictic mixing type (Fig. 7). In the comparatively cold winter of 2016/2017, however, inverse stratification still persisted at this warming rate under all the withdrawal scenarios. Furthermore, it is possible to obtain the same inversion duration under different air

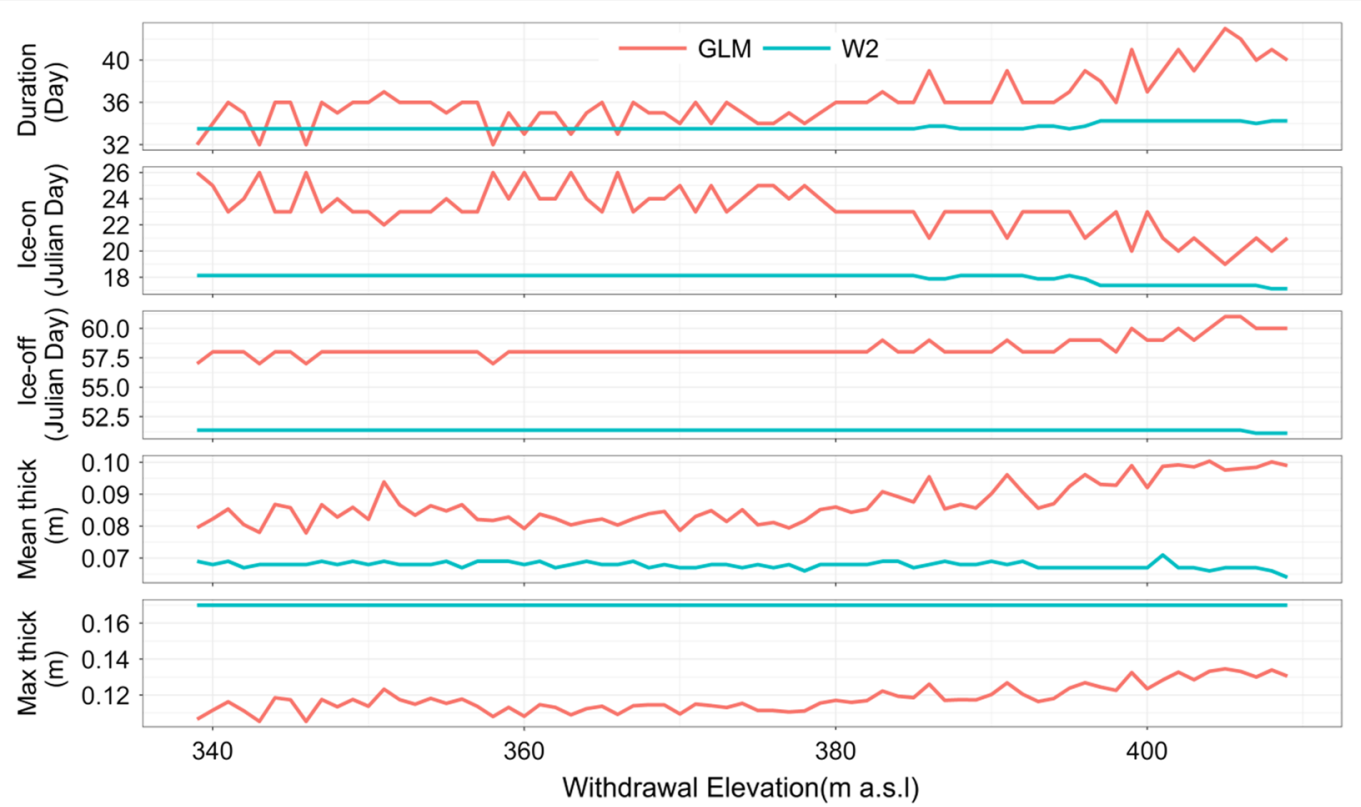

Fig. 6 Simulation results for ice cover duration, dates of ice-on and ice-off as well as mean and maximum ice thickness for W2 and GLM at different withdrawal elevations during winter 2016/2017 


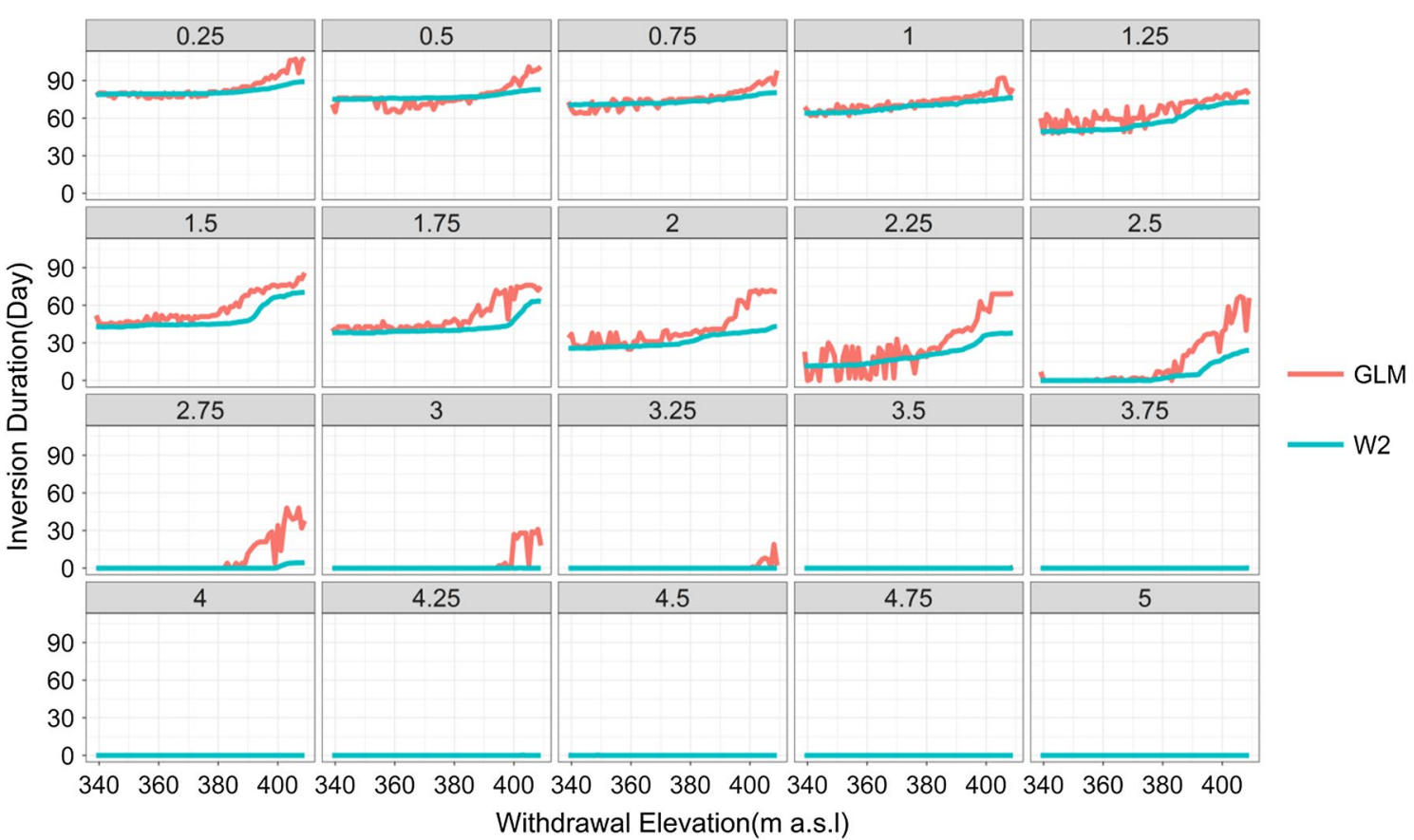

Fig. 7 Response of the duration of inversed stratification in winter 2015/2016 to changes in air temperature (y-axis) and withdrawal elevation (x-axis)

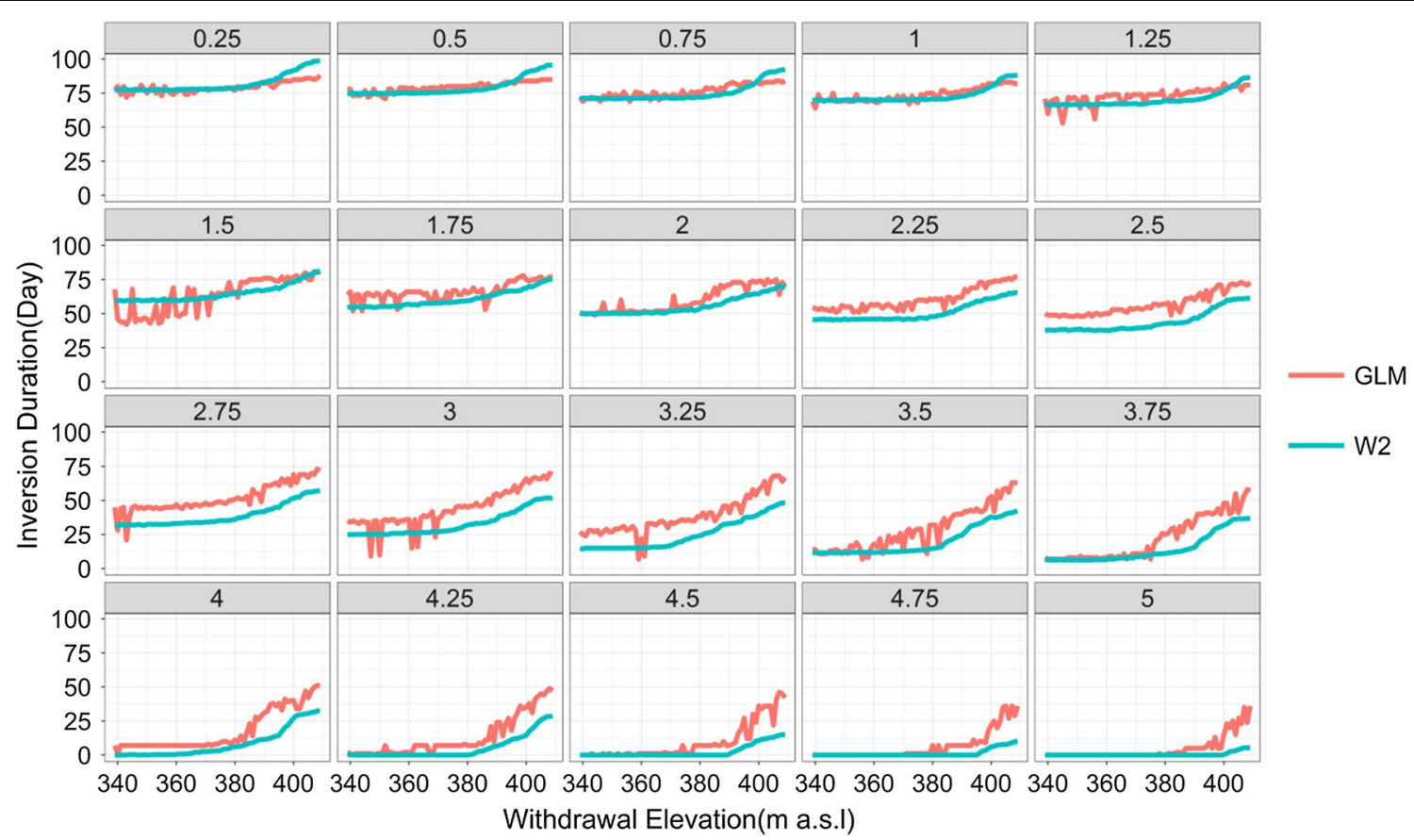

Fig. 8 Response of the duration of inversed stratification in winter 2016/2017 to changes in air temperature (y-axis) and withdrawal elevation (x-axis) 
temperature increases by adapting the withdrawal elevation accordingly (see Fig. 9). According to the results from W2, for example, the inversion duration in the winter of 2016/2017 at $1 \mathrm{~K}$ warming increased gradually from 70 days (withdrawal elevation below $380 \mathrm{~m}$ a.s.l.) to 88 days (withdrawal elevation at $409 \mathrm{~m}$ a.s.l.); under $1.75 \mathrm{~K}$ warming the inverse duration can occur for 54 days (bottom withdrawal) or up to 75 days (surface withdrawal). When adjusting the withdrawal elevation to either bottom withdrawal (at $1 \mathrm{~K}$ warming) or around $403 \mathrm{~m}$ a.s.l (at $1.75 \mathrm{~K}$ warming), in consequence, the duration of winter inverse stratification is about the same. The effects from warming in winter conditions can thus be compensated by adjusting the withdrawal elevation to a specifically shallower depth.

However, Figs. 7 and 8 also indicate that the performance of inversion stratification differs between the two models. In each subplot, the inversion duration calculated from W2 shows much smoother changes than that from GLM, which showed discontinuous shifts in the predicted inversion duration making the exact quantitative outcome highly dependent on small-scale variations in the simulation settings (e.g., in our case exemplified by the withdrawal elevation). It also appears that, compared to W2, the reaction of GLM to the variation in air temperature and withdrawal elevation was far more sensitive. The qualitative response patterns to warming and withdrawal elevation, however, remained independent of the model, as GLM and W2 showed similar response shapes. Noteworthy, in all the climate scenarios, the stratification durations obtained from both models are close to each other. It should also be noted that, for the winter of $2015 / 2016$, the inversion event began to disappear when air temperature increases beyond $2.25 \mathrm{~K}$ and $2.5 \mathrm{~K}$, for GLM and W2, respectively. In the winter of 2016/2017,

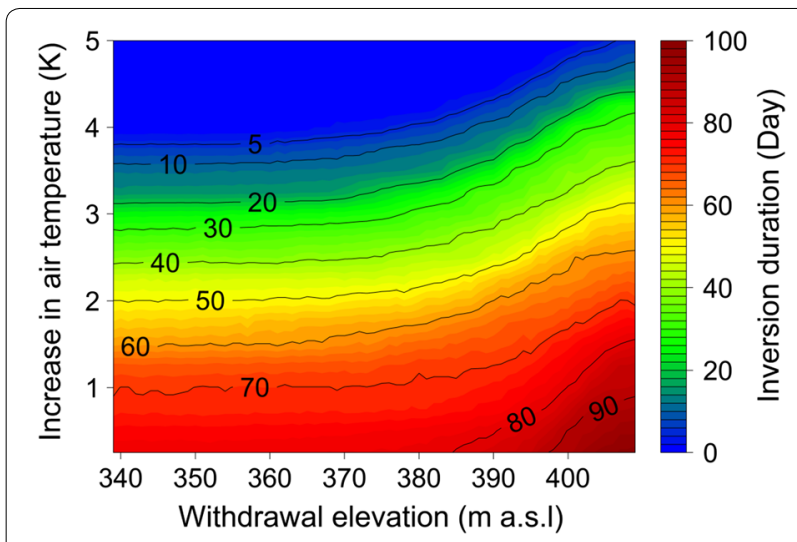

Fig. 9 Combined effects of changes in withdrawal elevation and air temperature on the duration of winter inversed stratification (for winter 2016/2017, from W2) the current air temperature should be increased by $4.5 \mathrm{~K}$ and $4 \mathrm{~K}$ for the two models so as to get the same effect.

\section{Discussion}

In this study, we used two hydrodynamic models, GLM and W2, to investigate the dynamics of the thermal structure and ice cover in the Rappbode Reservoir. The simulations of both models performed well in reproducing the water temperatures during the calibrated period $(01 / 2015$ to $04 / 2017$, see Fig. 3$)$. For the model calibration, the overall RMSE are $0.87 \mathrm{~K}$ (GLM) and $0.71 \mathrm{~K}$ (W2), both of which are lower than the errors presented in recent studies in which the two models were applied $[6,16,25,28,32,35]$. Although the models slightly overestimated the metalimnetic temperature in the summer and early autumn (in particular GLM, see Fig. 4), they performed well in reproducing the variation of surface temperature and stable temperature in the hypolimnion. The discrepancies between observed and simulated water temperatures may be linked to the insufficient modeling of internal waves, which has been shown to have a significant influence on the thermal dynamics in the Rappbode Reservoir [3]. This process is fundamentally three dimensional so that it cannot be fully captured by $1 \mathrm{D}$ or $2 \mathrm{D}$ models. Moreover, both the models use a constant light attenuation coefficient $\left(K_{\mathrm{w}}\right)$ which in reality is dynamic due to varying concentrations of algae and turbidity. As indicated by Bueche et al. [8], no provision of the seasonal variation of $K_{\mathrm{w}}$ in the input file may also exert a negative influence on the simulation accuracy.

An ice cover was not present in the Rappbode Reservoir every winter; hence, capturing the occurrence of ice in different years can be an important criterion to compare model capability when simulating ice dynamics. For the ice component, GLM performed better than W2 because the former simulated the ice occurrence only for the winter of 2016/2017 which is consistent with the observations. For W2, there were 52 days of thin ice cover $(<5 \mathrm{~cm})$ during the winter of 2015/2016 (Fig. 5), although no ice was observed in that period. The appearance of additional ice in W2 can be linked to the fact that the model underestimates the surface temperature of that winter (see Fig. 4). GLM accurately reproduced the ice-on date for the 2016/2017 winter, but the simulated ice-off date was delayed by 5 days compared to the observation. These results are in accordance with the previous finding by Yao et al. [48]. In their study, GLM was used to predict the ice cover of Harp Lake (Canada) under a future warming climate and the simulated ice-off dates were always later than expected. The delay of iceoff in both results shows that it is necessary to further improve the ice decay process in the model. We noted a few cases with negative surface water temperatures 
in W2, a phenomenon that is explained by the model specifications on ice dynamics. W2 applies a minimal ice thickness and during cooling episodes, negative water temperatures are accumulated before ice cover is formed in the simulation.

The different performance of inversion stratification between the two models can be clearly seen in Figs. 7 and 8. Compared to W2, the response of GLM seems overly sensitive to small changes in input (e.g., withdrawal elevation and air temperature). It seems that GLM reacts in a discontinuous way to changes in model parameters or model input data, which was already observed in previous research by Bueche et al. [8]. It goes beyond the scope of this study to identify the reasons for this problematic behavior in GLM. We also do not exactly know why both models perform differently in our scenarios, although it is obvious that both models have clear differences, e.g., in grid architecture (Lagrangian vs. Eulerian), heat budget calculations, or mixing algorithms. The fact that different models react differently in simulations with the same external drivers is due to structural differences between models (structured uncertainty). The application of model ensembles is the common strategy to account for structural uncertainty, e.g., in hydrology [2] or atmospheric sciences [43]. In lake modeling, however, the application of model ensembles is still rare although they were proven useful [44]. In conclusion, we believe that the application of two models is a major strength of our approach, because we can show that quantitative results vary between models but the basic outcome is independent of the used model. We encourage future lake model studies to exploit multi-model ensembles wherever possible to provide information on structural model uncertainties and to improve the reliability of outcomes. Comparative model applications will furthermore help to identify the strengths and weaknesses of existing models.

Our study clearly elucidates the response of winter inversed stratification to climate change, combined with water management options. It is reasonable that climate warming leads to a shortening of the period of inversed stratification (see Figs. 7, 8) and the inversion phenomenon can entirely disappear if the air temperature is increased high enough. It implies that, under strong warming in the future, the Rappbode Reservoir may change into a monomictic mixing type. Our findings are confirmed by those of Kirillin [24] who predicts that by the end of the twenty-first century, most deep lakes in northeastern Germany will change their mixing type to warm monomictic [24]. In addition to this, our results indicate that under a small increase of air temperature (less than $3 \mathrm{~K}$ ), adjusting the withdrawal elevation can be used to manage the inversed stratification so as to mitigate the influence caused by climate warming. Under the same weather conditions, a shallower withdrawal elevation will result in longer inversed stratification and, in turn, can offset the effects of further warming. If the air temperature is increased too much (higher than $4 \mathrm{~K}$ ), however, the potential of withdrawal strategy to stabilize inversed stratification gradually diminishes. These findings complement the study of Kerimoglu and Rinke [23], which focused on the response of summer stratification to the changing withdrawal regime [23]. The latter study confirms that the surface withdrawal reduces the mixing events in summer. Our study emphasizes such effects on the thermal structure in winter, which were not addressed by Kerimoglu and Rinke [23]. A changing wind condition in a warmer climate may be able to modify stratification further (compare [30]), but only very high winter storms could prevent the occurrence of inversed stratification due to high mixing intensities.

The effect of the withdrawal strategies on the duration of winter inversed stratification can be explained by the difference in internal heat energy stored in the reservoir under different withdrawal elevations. The deeper water withdrawals will store more heat energy in the reservoir. For example, we compared the internal heat energy under the real climatological conditions based on the surface ( $409 \mathrm{~m}$ a.s.l) and bottom ( $340 \mathrm{~m}$ a.s.l) withdrawal elevations (see Fig. 10). The heat energy per surface area can be defined as:

$$
E=\frac{\int_{0}^{z_{\max }} C T \rho_{z} A_{z} \mathrm{~d} z}{A_{0}},
$$

where $C$ is the specific heat capacity of water $(4186 \mathrm{~J} /$ $\mathrm{kg} / \mathrm{K}$ ), $T$ is the water temperature (in ${ }^{\circ} \mathrm{C}$ ), $\rho_{z}$ is the water density, $A_{z}$ is the area at depth $z, A_{0}$ is the surface area, and $Z_{\max }$ is the maximum water depth. It can be seen that the internal heat energy of the water column using bottom withdrawal is far higher than that using surface withdrawal. Therefore, bottom withdrawal will enlarge the heat storage and by that delay the occurrence of inversed stratification, because longer periods of cold weather are required to release the stored heat out of the water body.

Previous studies have shown that, under climate warming, numerous dimictic water bodies have the potential to change to a monomictic mixing type which may result in a negative influence on lentic aquatic ecosystems $[17,33]$. Our results indicate that the withdrawal elevation can be used as a management method to mitigate the negative influence caused by warming on the mixing regime. This option is only available in reservoirs with flexible outtake structures, while it is unavailable in natural lakes that always withdraw from the surface. Nevertheless, a change from dimictic to warm monomictic in a warmer world can in fact be avoided in many temperate reservoirs by 


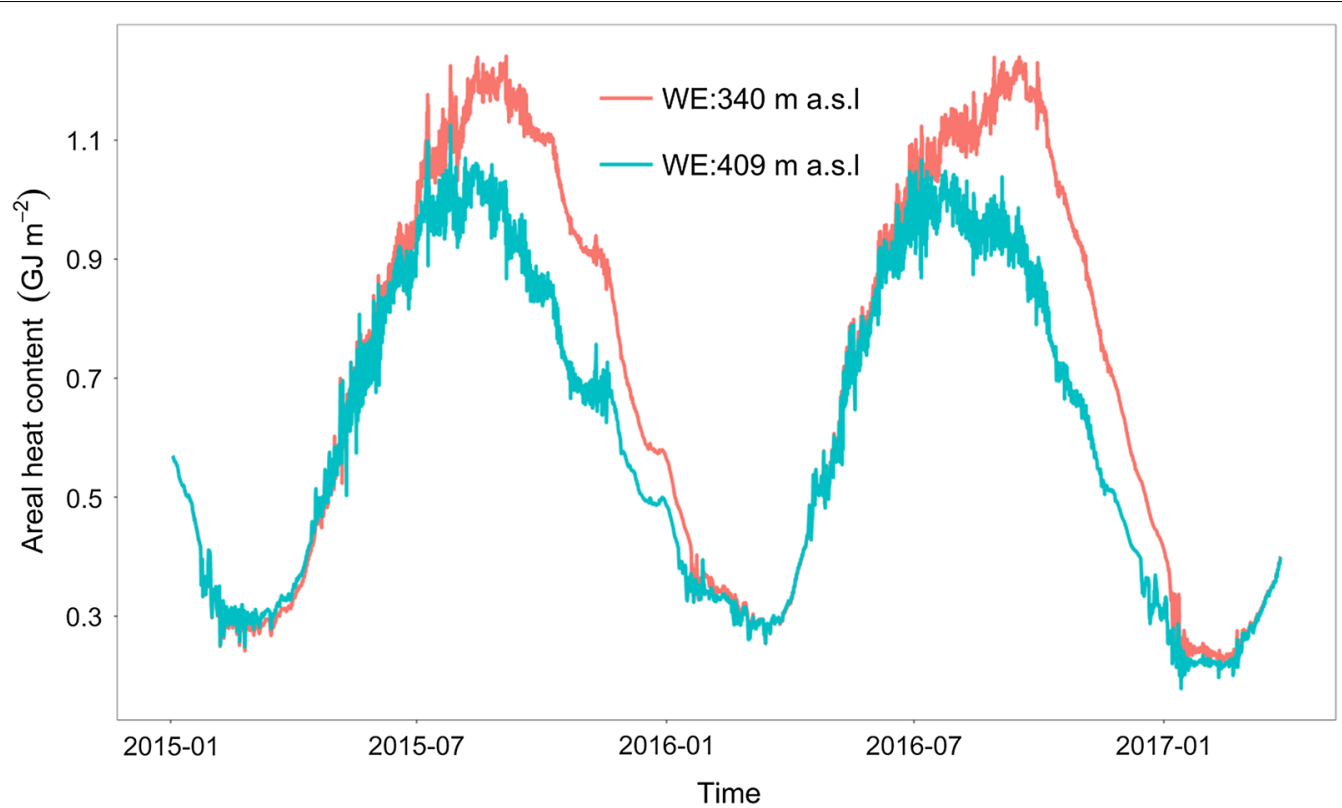

Fig. 10 Internal heat content per surface under surface (green line) and bottom (red line) withdrawal strategy (from W2)

adjusting the withdrawal elevation. This is a new management option in reservoir management that can be relevant for many reservoirs and overlooked in reservoir operation, which typically do not make much use of withdrawal elevation as a management instrument. Before implementation of a changing withdrawal management, however, potential side effects on water quality need to be evaluated, e.g., on deep water oxygen content, internal loading, and nutrient export. Therefore, it is worthwhile for future work to elucidate the response of other water quality variables (i.e., oxygen, nutrients, toxins) to these withdrawal strategies and to integrate such strategies into the multi-objective view required in sustainable reservoir management [40, 45].

\section{Conclusions}

- Two well-established hydrodynamic models (GLM and W2) showed good performance in reproducing the water temperature and ice cover in the Rappbode Reservoir, the largest drinking water reservoir in central Germany.

- Winter inversed stratification of the reservoir can entirely disappear under the current management regime if climate warming gets strong ( $>4 \mathrm{~K}$ warming). In other words, the Rappbode Reservoir may change from a dimictic to a monomictic mixing type under strong climate warming.

- Adjusting the withdrawal strategies can strongly influence the winter conditions and can mitigate the effect of climate warming on mixing type. Shallow withdrawal elevations will reduce internal heat energy stored in the reservoir over the summer and thus enable to conserve the dimictic state even in a much warmer climate ( $>4 \mathrm{~K})$.

- Withdrawal management is a so-far largely unexploited operational tool in climate change mitigation in reservoirs of the temperate zone.

\section{Abbreviations}

1D: one dimensional; 2D: two dimensional; GLM: General Lake Model; W2: CE-QUAL-W2; $m$ a.s.l: meters above sea level; WE: withdrawal elevation; CTD: conductivity temperature depth; RMSE: root-mean-square error.

\section{Authors' contributions}

CM and AS conducted GLM and W2 modeling approach, respectively. CM and KR analyzed the data and wrote the manuscript. KL reviewed, edited, and proofread the manuscript. All authors read and approved the final manuscript.

\section{Author details}

${ }^{1}$ Department of Lake Research, Helmholtz Centre for Environmental Research, Magdeburg, Germany. ${ }^{2}$ College of Water Conservancy, Shenyang Agricultural University, Shenyang, China. ${ }^{3}$ Global Institute for Water Security, University of Saskatchewan, Saskatoon SK S7N 3H5, Canada.

\section{Acknowledgements}

The authors would like to thank the Rappbode Reservoir authority (Talsperrenbetrieb Sachsen-Anhalt), the Fernwasserversorgung Elbaue-Ostharz GmbH, and the German Weather Service (DWD) for provision of the hydrological, limnological, and meteorological data. We are also grateful to Philipp Keller for preparing the bathymetric map. Finally, we thank the four anonymous reviewers for their constructive comments on an earlier version of this manuscript. 


\section{Competing interests}

The authors declare that they have no competing interests.

\section{Availability of data and materials}

The datasets used and analyzed during the current study are available from the corresponding author on reasonable request.

\section{Consent for publication}

Not applicable.

\section{Ethics approval and consent participate}

Not applicable.

\section{Funding}

The research was funded by the China Scholarship Council (CSC), the Priority Programme "Flexibility matters: Interplay between trait diversity and ecological dynamics using aquatic communities as model systems (Dynatrait)" of the German Science Foundation (Grant Number RI 2040/2-1), as well as the German Federal Ministry of Education and Research (BMBF, Grant Number 02WCL1337A). Funding was also provided by the Natural Sciences and Engineering Research Council of Canada's Discovery Grant.

\section{Publisher's Note}

Springer Nature remains neutral with regard to jurisdictional claims in published maps and institutional affiliations.

Received: 22 December 2018 Accepted: 2 March 2019 Published online: 11 March 2019

\section{References}

1. Adrian R, O'Reilly CM, Zagarese H, Baines SB, Hessen DO, Keller W Livingstone DM, Sommaruga R, Straile D, Van Donk E, Weyhenmeyer GA Winder M (2009) Lakes as sentinels of climate change. Limnol Oceanogr 54:2283-2297

2. Ajami NK, Duan Q, Sorooshian S (2007) An integrated hydrologic Bayesian multimodel combination framework: confronting input, parameter, and model structural uncertainty in hydrologic prediction. Water Resour Res. https://doi.org/10.1029/2005WR004745

3. Bocaniov SA, Ullmann C, Rinke K, Lamb KG, Boehrer B (2014) Internal waves and mixing in a stratified reservoir: insights from three-dimensional modeling. Limnologica 49:52-67

4 Boehrer B, Schultze M (2008) Stratification of lakes. Rev Geophys 46:RG 2005

5. Boehrer B, Schultze M (2009) Density stratification and stability

6. Brito D, Ramos TB, Gonçalves MC, Morais M, Neves R (2018) Integrated modelling for water quality management in a eutrophic reservoir in south-eastern Portugal. Environ Earth Sci 77:40

7. Bruce LC, Frassl MA, Arhonditsis GB, Gal G, Hamilton DP, Hanson PC, Hetherington AL, Melack JM, Read JS, Rinke K, Rigosi A, Trolle D, Winslow L, Adrian R, Ayala Al, Bocaniov SA, Boehrer B, Boon C, Brookes JD, Bueche T, Busch BD, Copetti D, Cortes A, de Eyto E, Elliott JA, Gallina N, Gilboa Y, Guyennon N, Huang L, Kerimoglu O, Lenters JD, Maclntyre S, Makler-Pick V, McBride CG, Moreira S, Ozkundakci D, Pilotti M, Rueda FJ, Rusak JA, Samal NR, Schmid M, Shatwell T, Snorthheim C, Soulignac F, Valerio G, van der Linden L, Vetter M, Vincon-Leite B, Wang JB, Weber M, Wickramaratne C, Woolway RI, Yao HX, Hipsey MR (2018) A multi-lake comparative analysis of the General Lake Model (GLM): stress-testing across a global observatory network. Environ Model Softw 102:274-291

8. Bueche T, Hamilton DP, Vetter M (2017) Using the General Lake Model (GLM) to simulate water temperatures and ice cover of a medium-sized lake: a case study of Lake Ammersee, Germany. Environ Earth Sci 76:461

9. Çalışkan A, Elçi Ş (2009) Effects of selective withdrawal on hydrodynamics of a stratified reservoir. Water Resour Manag 23:1257-1273

10. Casamitjana X, Serra T, Colomer J, Baserba C, Pérez-Losada J (2003) Effects of the water withdrawal in the stratification patterns of a reservoir. Hydrobiologia 504:21-28

11. Chai T, Draxler RR (2014) Root mean square error (RMSE) or mean absolute error (MAE)? - Arguments against avoiding RMSE in the literature. Geosci Model Dev 7:1247-1250
12. Chang $\mathrm{CH}$, Cai LY, Lin TF, Chung CL, van der Linden L, Burch M (2015) Assessment of the impacts of climate change on the water quality of a small deep reservoir in a humid-subtropical climatic region. Water 7:1687-1711

13. Cole TM, Wells SA (2006) CE-QUAL-W2: a two-dimensional, laterally averaged, hydrodynamic and water quality model, version 3.5

14. Coloso JJ, Cole JJ, Pace ML (2011) Short-term variation in thermal stratification complicates estimation of lake metabolism. Aquat Sci 73:305-315

15. England $\mathrm{MH}$, Kajtar JB, Maher N (2015) Robust warming projections despite the recent hiatus. Nat Clim Change 5:394-396

16. Fenocchi A, Rogora M, Sibilla S, Dresti C (2017) Relevance of inflows on the thermodynamic structure and on the modeling of a deep subalpine lake (Lake Maggiore, Northern Italy/Southern Switzerland). Limnologica 63:42-56

17. Ficker H, Luger M, Gassner H (2017) From dimictic to monomictic: empirical evidence of thermal regime transitions in three deep alpine lakes in Austria induced by climate change. Freshw Biol 62:1335-1345

18. Foley B, Jones ID, Maberly SC, Rippey B (2012) Long-term changes in oxygen depletion in a small temperate lake: effects of climate change and eutrophication. Freshw Biol 57:278-289

19. Friese K, Schultze M, Boehrer B, Büttner O, Herzsprung P, Koschorreck M, Kuehn B, Rönicke H, Wendt-Potthoff K, Wollschläger U (2014) Ecological response of two hydro-morphological similar pre-dams to contrasting land-use in the Rappbode reservoir system (Germany). Int Rev Hydrobiol 99:335-349

20. Hipsey MR, Bruce LC, Boon C, Busch B, Carey CC, Hamilton DP, Hanson PC, Read JS, de Sousa E, Weber M, Winslow LA (2019) A General Lake Model (GLM 2.4) for linking with high-frequency sensor data from the Global Lake Ecological Observatory Network (GLEON). Geosci. Model Dev. Discuss. https://doi.org/10.5194/gmd-2017-257

21. Hipsey MR, Bruce LC, Hamilton DP (2014) GLM-General Lake Model: Model overview and user information. The University of Western Australia, Perth, Australia. AED Report \#26

22. Hu F, Bolding K, Bruggeman J, Jeppesen E, Flindt MR, Van Gerven L, Janse $\mathrm{JH}$, Janssen AB, Kuiper JJ, Mooij WM (2016) FABM-PCLake-linking aquatic ecology with hydrodynamics. Geosci Model Dev 9:2271-2278

23. Kerimoglu O, Rinke K (2013) Stratification dynamics in a shallow reservoir under different hydro-meteorological scenarios and operational strategies. Water Resour Res 49:7518-7527

24. Kirillin G (2010) Modeling the impact of global warming on water temperature and seasonal mixing regimes in small temperate lakes. Boreal Environ Res 15:279-293

25. Ladwig R, Furusato E, Kirillin G, Hinkelmann R, Hupfer M (2018) Climate change demands adaptive management of urban lakes: model-based assessment of management scenarios for Lake Tegel (Berlin, Germany). Water 10:186

26. Lawrence MG (2005) The relationship between relative humidity and the dewpoint temperature in moist air: a simple conversion and applications. Bull Am Meteor Soc 86:225-234

27. Laybourn-Parry J, Wadham JL (2014) Antarctic Lakes

28. Lee R, Biggs T, Fang X (2018) Thermal and hydrodynamic changes under a warmer climate in a variably stratified hypereutrophic reservoir. Water 10:1284

29. Marmorino G (1978) Warm bottom water in lake Michigan. Limnol Oceanogr 23:1017-1020

30. Mi C, Frassl MA, Boehrer B, Rinke K (2018) Episodic wind events induce persistent shifts in the thermal stratification of a reservoir (Rappbode Reservoir, Germany). Int Rev Hydrobiol 103:71-82

31. Paerl HW, Huisman J (2009) Climate change: a catalyst for global expansion of harmful cyanobacterial blooms. Environ Microbiol Rep 1:27-37

32. Park H, Chung S, Cho E, Lim K (2018) Impact of climate change on the persistent turbidity issue of a large dam reservoir in the temperate monsoon region. Clim Change 151:365-378

33. Peeters F, Livingstone DM, Goudsmit GH, Kipfer R, Forster R (2002) Modeling 50 years of historical temperature profiles in a large central European lake. Limnol Oceanogr 47:186-197

34. Read JS, Hamilton DP, Jones ID, Muraoka K, Winslow LA, Kroiss R, Wu CH Gaiser $E$ (2011) Derivation of lake mixing and stratification indices from high-resolution lake buoy data. Environ Model Softw 26:1325-1336 
35. Read JS, Winslow LA, Hansen GJA, Van den Hoek J, Hanson PC, Bruce LC, Markfort CD (2014) Simulating 2368 temperate lakes reveals weak coherence in stratification phenology. Ecol Model 291:142-150

36. Rinke K, Kuehn B, Bocaniov S, Wendt-Potthoff K, Buttner O, Tittel J, Schultze M, Herzsprung P, Ronicke H, Rink K, Rinke K, Dietze M, Matthes M, Paul L, Friese K (2013) Reservoirs as sentinels of catchments: the Rappbode Reservoir Observatory (Harz Mountains, Germany). Environ Earth Sci 69:523-536

37. Rosner R, Muller-Navarra DC, Zorita E (2012) Trend analysis of weekly temperatures and oxygen concentrations during summer stratification in Lake Plusssee: a long-term study. Limnol Oceanogr 57:1479-1491

38. Sadeghian A, de Boer D, Hudson JJ, Wheater H, Lindenschmidt KE (2015) Lake Diefenbakertemperature model. J Gr Lakes Res 41:8-21

39. Sadeghian A, Chapra SC, Hudson J, Wheater H, Lindenschmidt K-E (2018) Improving in-lake water quality modeling using variable chlorophyll a/ algal biomass ratios. Environ Model Softw 101:73-85

40. Schwefel R, Gaudard A, Wüest A, Bouffard D (2016) Effects of climate change on deep-water oxygen and winter mixing in a deep lake (Lake Geneva) — comparing observational findings and modeling. Water Resour Res 52:8811-8826

41. Shimoda Y, Azim ME, Perhar G, Ramin M, Kenney MA, Sadraddini S, Gudimov A, Arhonditsis GB (2011) Our current understanding of lake ecosystem response to climate change: what have we really learned from the north temperate deep lakes? J Great Lakes Res 37:173-193
42. Snortheim CA, Hanson PC, McMahon KD, Read JS, Carey CC, Dugan HA (2017) Meteorological drivers of hypolimnetic anoxia in a eutrophic, north temperate lake. Ecol Model 343:39-53

43. Tebaldi C, Knutti R (2007) The use of the multi-model ensemble in probabilistic climate projections. Philos Trans R Soc A Math Phys Eng Sci 365:2053-2075

44. Trolle D, Elliott JA, Mooij WM, Janse JH, Bolding K, Hamilton DP, Jeppesen E (2014) Advancing projections of phytoplankton responses to climate change through ensemble modelling. Environ Model Softw 61:371-379

45. Weber M, Rinke K, Hipsey M, Boehrer B (2017) Optimizing withdrawal from drinking water reservoirs to reduce downstream temperature pollution and reservoir hypoxia. J Environ Manag 197:96-105

46. Winslow LA, Hansen GJA, Read JS, Notaro M (2017) Large-scale modeled contemporary and future water temperature estimates for 10774 Midwestern US Lakes. Sci Data 4:170053

47. Woolway RI, Maberly SC, Jones ID, Feuchtmayr H (2014) A novel method for estimating the onset of thermal stratification in lakes from surface water measurements. Water Resour Res 50:5131-5140

48. Yao H, Samal N, Joehnk K, Fang X, Bruce L, Pierson D, Rusak J, James A (2014) Comparing ice and temperature simulations by four dynamic lake models in Harp Lake: past performance and future predictions. Hydrol Process 28:4587-460

\section{Submit your manuscript to a SpringerOpen ${ }^{\odot}$ journal and benefit from:}

- Convenient online submission

$\checkmark$ Rigorous peer review

- Open access: articles freely available online

- High visibility within the field

- Retaining the copyright to your article

Submit your next manuscript at $\boldsymbol{\nabla}$ springeropen.com 